\section{Shift of Aromatic Band in Substituted Benzene}

The aromatic band ${ }^{1}$ found in benzene at $671 \mathrm{~cm}^{-1}$ shifts as a consequence of mono-substitution (in benzene) to $740-760 \mathrm{~cm}^{-1}$. In the case of di-substituted benzenes, there is a steady movement to higher frequencies in passing from the ortho- to the para-position; whereas in the case of para-substituted phenols we find that increase in molecular weight of the para-substituent from methyl to octyl does not shift the absorption band, which is found in all these compounds at $825-830 \mathrm{~cm}^{-1}$. Less extensive data on the ortho-phenols show no drift in the aromatic band at $750-755 \mathrm{~cm}^{-1}$ as a result of change in the molecular weight of the substituent from methyl to isopropyl. $m$-Cresol and $m$-ethyl phenol absorb strongly at $780-785 \mathrm{~cm}^{-1}$. It would appear that increasing molecular weight by aliphatic substituents does not shift the aromatic band in the mono-substituted phenols.

In the case of di-substituted phenols the following data were obtained

\begin{tabular}{|c|c|c|c|}
\hline $\begin{array}{l}1: 2: 5 \\
1: 2: 5 \\
1: 3: 5 \\
1: 3: 5\end{array}$ & $\begin{array}{l}\mathrm{OH}: \mathrm{CH}_{\mathrm{a}}: \mathrm{CH}_{8} \\
\mathrm{OH}: \mathrm{C}_{2} \mathrm{CH}_{8}: \mathrm{CH}_{8} \\
\mathrm{OH}: \mathrm{CH}_{\mathrm{g}}: \mathrm{CH}_{3} \\
\mathrm{OH}: \mathrm{CH}_{8}: \mathrm{C}_{2} \mathrm{H}_{8}\end{array}$ & $\begin{array}{l}800 \\
815 \\
830 \\
850\end{array}$ & $\begin{array}{c}\mathrm{cm} .^{-1} \\
" \\
"\end{array}$ \\
\hline
\end{tabular}

While the shift of the aromatic band, as a result of a change from methyl to ethyl in one of the two substituents of phenol, is rather more, especially in the case of the $1: 3: 5$ derivatives, than in the case of the mono-substituted phenols, it should be noted that Whiffen and Thompson's data show a shift of $15 \mathrm{~cm}^{-1}$ in moving from methyl to ethyl in the case of mono-substituted benzenes, and a shift of $36 \mathrm{~cm} .^{-1}$ in the case of $p$-xylene and $p$-ethyl toluene. Finally, in the case of 1 -hydroxy $2: 3: 5$ methyl benzene, the aromatic band is found at $840 \mathrm{~cm}^{-1}$. Comparison of this tetra-substituted benzene with the related trisubstituted benzenes is given below :

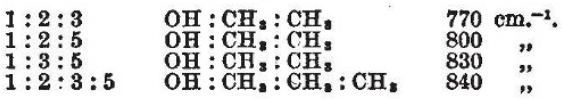

It is evident that adjacency of substituents and degree of substitution affect the shifting of the band, to a greater extent in general than increase in molecular weight of the substituent.

I am indebted to Mr. J. S. M. McKe日, who carried out the experimental work.

\section{J. S. GouRLAY}

Imperial Chemical Industries, Ltd.,

(Paints Division),

IVexham Road,

Slough.

Nov. 29.

'Whiffen and Thompson, J. Chem. Soc., 268 (1945).

\section{Rate of Growth of Current in Arc Discharges}

IF a condenser, charged to a few hundred volts, is connected directly across a small two-electrode tube containing rarefied gas, and a discharge initiated by applying a high-tension triggering pulse near the cathode, the condenser will be discharged in a few microseconds. The discharge is a form of arc, since a 'cathode spot' is necessary to supply the very high currents (a thousand amperes or more) needed to do this, and the applied potential is lower than that associated with glow or spark discharges.
These arcs have been used by many investigators ${ }^{x}$ in order to obtain photographs of rapidly moving objects; but a study of the factors within the tube which determine the rate of growth of current seems to have been neglected.

As a result of such a study $I$ have reached the following conclusions about the early stages (that is, the first microsecond) of the discharge. The current density of emission from the cathode spot is greater than $10^{6}$ amp. per sq. cm., and this emitting area generally races over the surface of the cathode at such a velocity that it moves on to new territory in about $10^{-7}$ sec. Even at such an emission current density, the cathode does not become unduly heated because of the velocity of the spot; thermionic emission is thus very unlikely.

This current density is sufficiently high for field emission to be the most probable cause of the electron current from the cathode. On this assumption one might expect the current in the tube to rise as rapidly as positive ions can be created and carried to the cathode from the 'positive column' close to it. Nearly all the applied potential appears to be taken up by this column. The rate of growth of current is, in fact, found to be greater for a residual gas the ionization coefficient (that is, the number of ion pairs created per cm. per electron) of which is high, and is also increased to a lesser extent by using lighter gases.

For example, in a tube with electrode spacing about $15 \mathrm{~mm}$., connected across a condenser of capacity 2 microfarads charged initially to 300 volts, the current rises from about $1 \mathrm{amp}$. to $10 \mathrm{amp}$. in about $12 \times 10^{-8}$ sec. with the tube filled with air at $2 \mathrm{~mm}$. mercury pressure. It rises by this amount in $6 \times 10^{-8} \mathrm{sec}$. if filled with argon at $2 \mathrm{~mm}$. pressure, and takes about $4 \times 10^{-8}$ sec. if filled with helium at $2 \mathrm{~mm}$. pressure.

It is hoped to publish a fuller account of this work in due course elsewhere.

I am indebted to Sir George Thomson for valuable discussion and advice; and to Dr. M. Blackman for discussions on cathode heating.

\section{K. D. Froome}

(Beit Physics Fellow)

Imperial College of Science and Technology, London, S.W.7.

Dec. 4.

${ }^{1}$ For references, see Henry, J. Sei. Instr., 82, 135 (1944).

\section{Heat of Atomization of Carbon}

Is a private letter from Princeton dated April 26, 1939, Prof. A. G. Shenstone reported the following observation: "In all cases where I have photographed arcs in $\mathrm{N}_{2}$ using carbon electrodes $\mathbf{I}$ have observed three lines which act like C I lines although I have found no trace of them in the literature. They are in the correct position and have proper intervals to be $s p^{3}{ }^{5} S-s p^{2} s{ }^{5} P$. They are quite sharp and I think my measures are probably good to $\pm 0.01 \mathrm{~A}$. :

\begin{tabular}{|c|c|c|c|c|c|}
\hline$\stackrel{\lambda}{\lambda} \cdot 1431 \cdot 595$ & 20 & $69852 \cdot 1$ & \multirow{3}{*}{$\begin{array}{l}25 \cdot 3 \\
20 \cdot 6\end{array}$} & \multicolumn{2}{|c|}{$s p^{2}{ }^{5} S_{2}-s p^{2} 3 s{ }^{s} P_{3}$} \\
\hline $1432 \cdot 115$ & 15 & $69826 \cdot 8$ & & - & $\Delta P_{2}$ \\
\hline $432 \cdot 538$ & 10 & $69806 \cdot 2$ & & - & ${ }^{s} P_{t}{ }^{\prime \prime}$ \\
\hline
\end{tabular}

The suggested identification of Shenstone's lines is strongly supported by the iso-electronic comparison, as shown in the accompanying table, and is no doubt 